\title{
ANALISIS POTENSI CADANGAN KARBON UNTUK PENGELOLAAN HUTAN DI TAMAN WISATA ALAM DANAU BUYAN-DANAU TAMBLINGAN
}

\author{
Bernadina Paulinda Maku $^{1 *)}$, I Wayan Suarna ${ }^{2)}$, I Wayan Diara ${ }^{\text {3) }}$ \\ ${ }^{1)}$ Program Studi Magister Ilmu Lingkungan, Universitas Udayana \\ ${ }^{2)}$ Program Studi Peternakan, Fakultas Peternakan, Univesitas Udayana \\ ${ }^{3)}$ Program Studi Agroteknologi, Fakultas Pertanian, Universitas Udayana \\ *Email: meyamaku1@gmail.com
}

\begin{abstract}
ABSTRACK
ANALYSIS OF POTENTIAL CARBON STOCK FOR FOREST MANAGEMENT AT TAMAN WISATA ALAM DANAU BUYAN- DANAU TAMBLINGAN
\end{abstract}

\begin{abstract}
Taman Wisata Alam (TWA) Danau Buyan-Danau Tamblingan one of the forest ecosystems that are rich in biodiversity. The information about carbon stocks stored at the surface of the soil is very important to know in order to improvements can be made to the cultivation technique, plant type selection, and right forest management to maintain and increase carbon stocks. The study aimed: calculating and knowing the factors behind the difference carbon stocks above ground level, litter, and soil at Buyan Lake forest and Tamblingan Lake forest and formulating management strategy of TWA Danau Buyan-Danau Tamblingan for supports increased forest carbon stocks. Whereases the measurements carbon stock at medium, low and high density. To formulate management directives used the SWOT analysis. The result of this study is: carbon stocks in above ground level, litter and soil at Buyan Lake forest smaller than Tamblingan Lake forest, with the following details Buyan Lake forest, was: 613.03 ton/ha, 62.56 ton/ha and 125.443 ton/ha whereas Tamblingan Lake forest was: 768.93 ton/ha, 105.26 ton/ha and 360.711 ton/ha, factors causing differences in carbon stocks at Buyan Lake forest and Tamblingan Lake Forest is the variety of plants that dominate and the human activity. Management strategy of TWA is: provide assistance to the community to proposing Izin Pengusahaan Pariwisata Alam (IPPA), facilitated indigenous villages to gain recognition of customary forests and formulated awig-awig as local wisdom in management of TWA Danau Buyan-Danau Tamblingan.
\end{abstract}

Keywords: Carbon stock; Forest management strategies; analysis SWOT; TWA Danau Buyan Danau Tamblingan.

\section{PENDAHULUAN}

Hutan memainkan peranan yang penting dalam siklus karbon global dan dapat menyimpan karbon sekurang-kurangnya 10 kali lebih besar dibandingkan dengan tipe vegetasi lain seperti padang rumput, tanaman semusim, dan tundra

(Holdgate, 1995). Kemampuan tegakan hutan untuk menyerap karbondioksida $\left(\mathrm{CO}_{2}\right)$ dan melepaskan oksigen $\left(\mathrm{O}_{2}\right)$ dalam proses fotosintesis serta menyimpannya di dalam vegetasi yang dikenal sebagai rosot karbon (carbon sink). Semakin banyak $\mathrm{CO}_{2}$ yang diserap oleh tumbuhan dan disimpan dalam bentuk biomassa karbon maka semakin besar pengaruh buruk efek rumah kaca dapat dikendalikan. Hutan memiliki setidaknya empat kolom karbon; biomassa atas permukaan (aboveground biomass), biomassa bawah permukaan (underground biomass), bahan organik mati (necromassa) dan kandungan organik tanah. 
Salah satu ekosistem hutan yang kaya akan keanekaragaman hayati, baik flora maupun fauna di Provinsi Bali adalah Taman Wisata Alam Danau Buyan-Danau Tamblingan. TWA ini merupakan salah satu kawasan konservasi di Pulau Bali yang ditetapkan melalui SK Menteri Kehutanan Nomor SK.2847/Menhut-VII/KUH/2014 dengan luas sebesar 1.847,38 Ha. Kawasan hutan sekitar Danau Buyan-Tamblingan merupakan kawasan hutan yang sangat berperan sebagai catchment area, persediaan air dan penunjang keberadaan ekosistem di Bali (BLH Bali, 2012). Kondisi kawasan hutan Danau Buyan dan Tamblingan mengalami beberapa permasalahan akibat faktor antropogenik seperti adanya alih fungsi lahan untuk aktifitas pertanian dan pembangunan di sempadan danau, serta pemanfaatan badan air danau sebagai tempat budidaya ikan dengan keramba jaring apung (KJA). Alih fungsi lahan di sempadan danau yang awalnya merupakan tanaman tahunan menjadi lahan pertanian tanaman semusim akan mempengaruhi kecepatan laju sedimentasi danau sehingga menyebabkan pendangkalan dan pengkayaan nutrien perairan danau akibat tercuci (leaching) oleh adanya erosi. Wilayah Danau Buyan memiliki indeks keanekaragaman jenis tanaman yang lebih tinggi dari Danau Tamblingan. Perbedaan tingkat keanekaragaman di kedua komunitas ini dapat terjadi karena salah satunya adalah meski kedua kawasan hutan merupakan kawasan wisata alam, namun kawasan hutan di Danau Buyan lebih banyak terdapat tekanan pariwisata, dengan dibukanya areal camping ground, aksesibilitas jalan hutan makin mudah, jalan juga sering dilalui oleh kendaraan, dan adanya konversi ke lahan pertanian, Sutomo dan Darma, (2011).

Informasi mengenai cadangan karbon yang tersimpan pada permukaan tanah seperti biomassa pohon, nekromasa, seresah dan juga kandungan karbon organik tanah pada berbagai tipe hutan, jenis pohon dan topografi sangat penting untuk ketahui agar dapat dilakukan perbaikan pada teknik budidaya, pemilihan jenis tanaman dan pengelolaan hutan yang tepat guna mempertahankan dan meningkatkan cadangan karbon, karena setiap pool karbon memiliki potensi untuk menjadi sumber emisi atau serapan GRK.

Tekanan aktivitas masyarakat telah merubah kondisi TWA Danau Buyan-Danau Tamblingan saat ini. Perubahan terhadap kondisi vegetasi di dalam kawasan hutan TWA Danau Buyan-Danau Tamblingan, akan berpengaruh pula pada tingkat kerapatan tanaman dan tentu saja pada kemampuan hutan menyimpan cadangan karbon. Oleh karena itu perlu dilakukan penelitian mengenai potensi cadangan karbon di kawasan hutan Danau Buyan dan Danau Tamblingan ini. Tujuan penelitian ini adalah (1) menghitung perbedaan cadangan karbon pada tiga karbon pool atas permukaan tanah (pohon dan tumbuhan bawah), nekromassa (seresah), dan tanah di hutan Danau Buyan dan Danau Tamblingan, (2) mengetahui faktor penyebab perbedaan cadangan karbon pada tiga karbon pool atas permukaan tanah (pohon dan tumbuhan bawah), nekromassa (seresah), dan tanah di hutan Danau Buyan dan Danau Tamblingan, dan (3) merumuskan arahan pengelolaan kawasan TWA Danau Buyan-Danau Tamblingan untuk mendukung peningkatan cadangan karbon hutan.

\section{METODOLOGI}

Penelitian ini menggunakan data pengukuran cadangan karbon pada kerapatan sedang, rendah dan tinggi di areal hutan Danau Buyan dan Danau Tamblingan. Metode yang digunakan adalah nondestructive sampling untuk tingkat pohon, tiang dan pancang sedangkan untuk tumbuhan bawah, seresah dan bahan organik tanah adalah destructive sampling. Untuk merumuskan arahan pengelolaan dilakukan dengan metode wawancara mendalam (indepth interview) kepada narasumber yaitu kepala resort, polisi kehutanan (polhut), Tenaga Pengamanan Hutan Lainnya (TPHL) di resort Konservasi Sumber Daya Alam Danau Buyan-Danau Tamblingan, Kepala 
Desa Pancasari, Kepala Desa Munduk, Kepala Dusun Dasong, Kepala Dusun Buyan dan Kepala Dusun. Penyebaran kuisioner dilakukan kepada masyarakat desa penyangga, kemudian dilanjutkan dengan analisis SWOT.

\subsection{Waktu dan Lokasi penelitian}

Penelitian ini dilakukan di hutan Danau Buyan dan Danau Tamblingan yang terletak di kawasan TWA Danau Buyan-Danau Tamblingan kelompok hutan Gunung Batukau. Penelitian dilakukan selama Bulan Januari sampai dengan Maret 2020.

\subsection{Penentuan Sampel Data}

Sampel data yang digunakan dalam penelitian ini adalah sampel responden dan sampel pengukuran cadangan karbon. Narasumber yang dipilih untuk dilakukan wawancara mendalam adalah adalah pengelola TWA Danau Buyan-Danau Tamblingan dalam hal ini adalah pihak Resort Danau Buyan-DanauTamblingan dan aparat desa penyangga wilayah TWA Danau Buyan-Danau Tamblingan. Untuk penentuan sampel respondennya dilakukan dengan menggunakan persaman Slovin, sehingga diperoleh sampel responden untuk Dusun Dasong sebanyak 73 KK, Dusun Buyan sebanyak $65 \mathrm{KK}$ dan Dusun Tamblingan sebanyak $85 \mathrm{KK}$.

Penentuan titik sampel untuk pengukuran potensi cadangan karbon dilakukan dengan pertimbangan intensitas kerapatan tajuk pohon menggunakan Citra Sentinel 2A, sehingga diperoleh tiga jenis kerapatan yaitu kerapatan sedang, rendah dan tinggi pada masing-masing lokasi seperti terlihat pada Gambar 1.

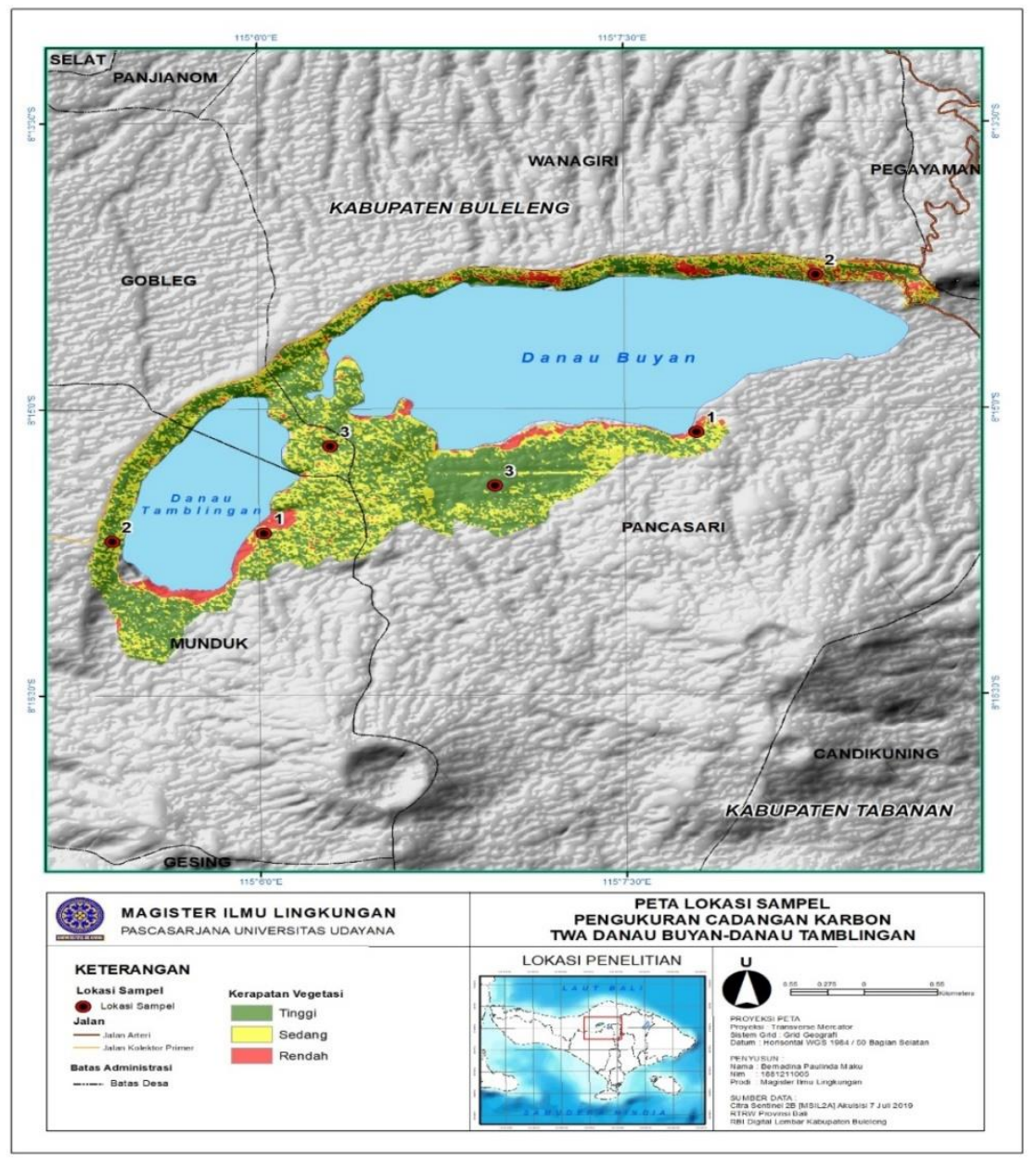

Gambar 1.

Enam Titk Sampel Pengukuran Potensi Cadangan Karbon 


\subsection{Bahan dan Instrumen Penelitian}

Bahan yang digunakan dalam penelitian ini adalah: citra sentinel 2A akuisisi 7 Juli 2019, peta lokasi penelitian, tally sheet, seresah, sampel tanah dari areal hutan Danau Buyan dan areal hutan Danau Tamblingan, dan kuisioneralat pengambil contoh tanah (soil ring sampler), ayakan tanah, meteran dan tali, peta kerja, oven, kertas label dan kantong/wadah contoh.

\subsection{Prosedur Penelitian}

Prosedur yang dilakukan dalam penelitian ini meliputi dua tahap yaitu; pengukuran cadangan karbon dan penyebaran kuisioner serta wawancara. Beberapa tahapan dalam pengukuran cadangan karbon adalah sebagai berikut: a) Penentuan lokasi penelitian dilakukan dengan teknik purposive sampling yaitu berdasarkan atas adanya pertimbangan yang berfokus pada tujuan tertentu, pertimbangan pertama yaitu perbedaan intensitas aktivitas manusia pada lokasi penelitian yaitu dibagi menjadi areal hutan Danau Buyan (lokasi I) dan areal hutan Danau Tamblingan (lokasi II).

b) Pembuatan petak ukur sesuai kondisi lapangan, ukuran petak ukur tiap tingkatan pertumbuhan vegetasi, semai dengan ukuran $2 \times 2 \mathrm{~m}$, pancang dengan ukuran $5 \times 5 \mathrm{~m}$, tiang dengan ukuran 10x10 $\mathrm{m}$ dan pohon dengan ukuran 20x20 m. Untuk lebih jelasnya terkait bentuk dan ukuran petak ukur dapat dilihat pada Gambar 2.

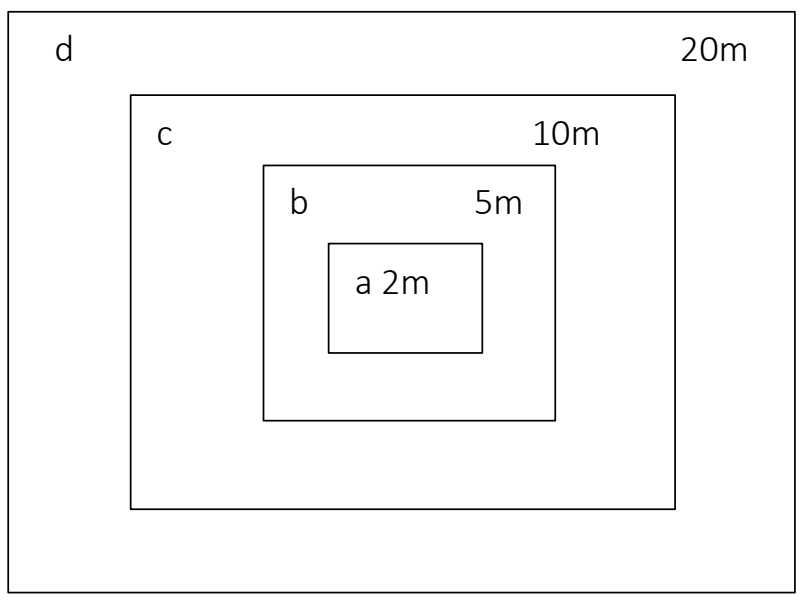

Gambar 2.

Bentuk dan ukuran petak ukur

c) Pengambilan data pohon, tiang dan pancang melalui pengukuran diameter pohon, sedangkan untuk tumbuhan bawah (understorey) dilakukan secara destructive pada subplot $2 \times 2 \mathrm{~m}$. Selanjutnya sampel dioven untuk mengetahui berat keringnya.

d) Pengambilan sampel seresah pada subplot $2 \times 2 \mathrm{~m}$. Selanjutnya sampel dioven untuk mengetahui berat keringnya.

e) Pengambilan sampel tanah. tanah terusik digunakan untuk mengetahui kandungam karbon dalam tanah, sedangkan tanah utuh untuk mengetahui berat volume tanah.
Wawancara mendalam dilakukan terhadap para narasumber, dengan daftar pertanyaan yang telah dipersiapkan terlebih dahulu. Penyebaran kuisioner kepada responden bertujuan untuk mengetahui persepsi masyarakat tentang pemanfaatan dan pengelolaan kawasan konservasi TWA Danau Buyan-Danau Tamblingan

\subsection{Perhitungan dan Analisis Data}

Data hasil pengukuran terhadap diameter, berat basah dan berat kering sampel tanaman maupun seresah dan tanah. Baik hasil pengukuran di lapangan maupun 
di laboratorium kemudian dilakukan pendugaan biomassa untuk selanjutnya dilakukan analisis untuk mendapatkan nilai cadangan karbon dari masing-masing kolom karbon tersebut. Rumus yang digunakan dalam perhitungan dan analisis data dalam penelitian ini adalah sebagai berikut:

1. Pendugaan biomassa pancang, tiang dan pohon menggunakan persamaan alometrik dengan persamaan sebagai berikut:

$\mathrm{W}=0.11 \rho \mathrm{D} 2.62$

(Ketterings et al., 2001)

Keterangan:

$\mathrm{W}=$ Biomassa pohon $(\mathrm{kg} / \mathrm{phn}) \quad \mathrm{D}=$ diameter $(\mathrm{cm})$

$\rho=$ berat jenis kayu $(\mathrm{g} / \mathrm{cm})$

Untuk nilai berat jenis dilihat pada buku Atlas Kayu Indonesia.

2. Biomassa tumbuhan bawah dihitung menggunakan persamaan sebagai berikut (Hairiah et.al., 2011):

$\mathrm{Btb}=(\mathrm{BKtb} \mid \mathrm{BBCtb}) \mathrm{xTBBtb}$

Keterangan:

Btb = Biomassa tumbuhan bawah (g)

$\mathrm{BKCtb}=$ Berat kering contoh tumbuhan bawah (g)

$\mathrm{BBCtb}=$ Berat basah contoh tumbuhan bawah (g)

TBB $\mathrm{tb}=$ Total berat basah tumbuhan bawah $(\mathrm{g})$

3. Biomassa nekromassa (seresah) dihitung dengan persamaan sebagai berikut (BSN, 2011):

$\mathrm{Bs}=(\mathrm{BKSs}$ |'BBss$) \mathrm{X}$ TBBs

Bss $\quad=$ Biomassa seresah $(\mathrm{g})$

BKSs $=$ Berat kering sampel seresah $(\mathrm{g})$

BBSs = Berat basah sampel seresah (g)

TBBs $=$ Total berat basah seresah (g)

4. Karbon organik tanah, dihitung menggunakan persamaan sebagai berikut:

$\mathrm{Ct}=\mathrm{Kt} \times \mathrm{Blt} \times \mathrm{Cot}$

Keterangan:

$\mathrm{Ct}=\operatorname{Karbon} \operatorname{tanah}\left(\mathrm{g} / \mathrm{cm}^{2}\right)$

$\mathrm{Kt}=$ Kedalaman tanah $(\mathrm{cm})$
BIt $=$ Berat isi tanah $(\mathrm{g} / \mathrm{cm} 3)$

Cot $=$ Kandungan C-organik tanah $(\%)$ berdasarkan hasil laboratorium

5. Karbon dari biomassa, menurut Badan Standarisasi Nasional (2011) adalah menggunakan persamaan sebagai berikut: $\mathrm{Cb}=\mathrm{W} \times 0.47$

Keterangan:

$\mathrm{Cb}=$ Kandungan karbon dari biomassa ( $\mathrm{kg})$

$\mathrm{W}=$ Total biomassa $(\mathrm{kg})$

$0.47=$ Nilai persentase kandungan karbon

6. Karbon dari tumbuhan bawah, menurut Badan Standarisasi Nasional (2011) adalah menggunakan persamaan sebagai berikut:

$\mathrm{Ctb}=\mathrm{B} \times 0.47$

Keterangan

$\mathrm{Cs}=$ Kandungan karbon dari tumbuhan bawah $(\mathrm{kg})$

$\mathrm{B}=$ Total biomassa tumbuhan bawah $(\mathrm{kg})$

$0.47=$ Nilai persentase kandungan karbon

7. Karbon dari nekromassa (seresah), menurut Badan Standarisasi Nasional (2011) adalah menggunakan persamaan sebagai berikut:

$\mathrm{Cs}=\mathrm{B} \times 0.47$

Keterangan:

Cs $=$ Kandungan karbon dari seresah (kg)

$\mathrm{B}=$ Total biomassa seresah $(\mathrm{kg})$

$0.47=$ Nilai persentase kandungan karbon

8. Kandungan karbon biomassa per hektar.

Penghitungan cadangan karbon per hektar untuk biomassa di atas permukaan tanah dapat menggunakan persamaan sebagai berikut:

$\mathrm{Cn}=\mathrm{Cx} / 1000 \times 10.000 /$ lplot

Keterangan:

$\mathrm{Cn}=$ kandungan karbon/hektar pada masing-masing carbon pool tiaptiap plot (ton/ha) 
$\mathrm{Cx}=$ kandungan karbon pada masingmasing carbon pool pada tiap plot $(\mathrm{kg})$

Lplot = luas plot pada masing-masing pool $\left(\mathrm{m}^{2}\right)$

9. Penghitungan kandungan karbon organik tanah per hektar, menggunakan persamaan sebagai berikut:

Ctanah $=\mathrm{Ct} \times 100$

Keterangan:

Ctanah = kandungan karbon organik tanah per hektar (ton/ha)

$\mathrm{Ct}=$ kandungan karbon tanah $(\mathrm{g} / \mathrm{cm} 2)$

$100=$ faktor konversi dari $\mathrm{g} / \mathrm{cm} 2 \mathrm{ke}$ ton/ha

10. Perhitungan karbon total dalam suatu lokasi berdasarkan Badan Standarisasi Nasional (2011) adalah menggunakan persamaan berikut:

Cplot $=(\mathrm{Cn}+\mathrm{Ctb}+\mathrm{Cs}+\mathrm{Ctanah})$

Keterangan:

Cplot $=$ Total kandungan karbon pada semua plot

$\mathrm{Cn}=$ Total kandungan karbon biomassa atas permukaan perplot

$\mathrm{Ctb}=$ Total kandungan karbon dari tumbuhan bawah perplot

Cs = Total kandungan karbon dari seresah perplot

Ctanah $=$ Total kandungan karbon organik tanah perplot
Data hasil wawancara dan kuisioner dianalisis menggunakan analisis SWOT untuk mendapatkan arahan pengelolaan hutan di TWA Danau Buyan-Danau Tamblingan. Proses pembuatan analisis SWOT dalam penelitian ini dilakukan melalui tiga tahap yaitu 1) identifikasi faktor internal dan faktor eksternal, 2) analisis faktor internal (IFAS) dan analisis faktor eksternal (EFAS), 3) merumuskan strategi pengelolaan TWA Danau Buyan-Danau Tamblingan menggunakan matriks analisis SWOT dan diagram analisis SWOT.

\section{HASIL DAN PEMBAHASAN}

\subsection{Potensi Cadangan Karbon di Taman Wisata Alam Danau Buyan-Danau Tamblingan}

Kandungan karbon yang dihitung dalam penelitian ini adalah karbon atas permukaan tanah dari tegakan, tumbuhan bawah dan seresah dan bahan organik tanah. Dari hasil pengukuran terhadap biomassa tegakan, biomassa tumbuhan bawah, biomassa seresah dan bahan organik tanah pada kawasan hutan Danau Buyan dan Danau Tamblingan diperoleh hasil seperti pada Tabel 1.

Tabel 1. Potensi simpanan karbon di TWA Danau Buyan-Danau Tamblingan

\begin{tabular}{llcc}
\hline No & \multicolumn{1}{c}{ Carbon pool } & \multicolumn{2}{c}{ Cadangan karbon (ton/ha) } \\
\cline { 3 - 4 } & & Buyan & Tamblingan \\
\hline 1 & Tegakan/pohon & 549.96 & 701.05 \\
& Tiang & 12.85 & 6.86 \\
& Pancang & 14.41 & 18.31 \\
& Tumbuhan bawah & 41.81 & 42.63 \\
& Sub total & $\mathbf{6 1 6 . 0 3}$ & $\mathbf{7 6 8 . 9 3}$ \\
2 & Nekromasa/Seresah & 62.56 & 105.26 \\
3 & Bahan organik tanah & 125.443 & 360.711 \\
\multicolumn{2}{c}{ Total } & $\mathbf{8 0 4 . 0 4}$ & $\mathbf{1 . 2 3 4 . 9 1}$ \\
\hline \multicolumn{2}{r}{} & &
\end{tabular}

Hasil penelitian menunjukan bahwa cadangan karbon atas permukaan tanah pada kawasan hutan sekitar Danau Buyan lebih rendah dibandingkan kawasan hutan Danau Tamblingan, baik pada tingkat tegakan, tumbuhan bawah maupun seresah. Perbedaan jumlah cadangan karbon pada kedua lokasi penelitian ini disebabkan oleh dua faktor. Faktor pertama adalah keragaman jenis tanaman yang mendominasi di hutan Danau 
Buyan lebih rendah dari hutan Danau Tamblingan. Jumlah karbon tersimpan dalam suatu tutupan lahan sangat bergantung pada keragaman jenis tanaman, kerapatan vegetasi, jenis tanah serta cara pengelolaannya. Hutan alami dengan keragaman jenis pepohonan berumur panjang dan seresah yang banyak merupakan gudang penyimpan karbon tertinggi dibandingkan hutan tanaman (Hairiah, et al. 2007). Hal ini terlihat pada jenis tanaman di kerapatan tinggi pada Danau Buyan didominasi oleh tanaman hasil reboisasi yaitu jenis Altingia excelsa Noronha (rasamala), sedangkan pada hutan Danau Tamblingan hampir seluruhnya adalah hutan alam yang didominasi oleh tegakan jenis Ficus spp dan Tabernaemontana, spp. Ficus memiliki fungsi ekologi antara lain ialah menjaga tata air serta menguatkan lereng secara alami karena struktur perakarannya yang mampu mengikat tanah dengan baik, kemudian melalui tajuk yang rimbun Ficus spp memiliki kemampuan yang tinggi untuk menyerap $\mathrm{CO}_{2}$ dan gas polutan lainnya di udara (Ulum, 2009). Faktor yang kedua adalah aktivitas masyarakat dalam kawasan hutan Danau Buyan yang memberikan tekanan terhadap jumlah vegetasi yang terdapat di dalam kawasan hutan, yaitu illegal logging, pengambilan kayu bakar untuk tingkatan kelas tiang dan pancang, aktivitas dalam kawasan hutan yang sering menggunakan kendaraan bermotor seperti aktivitas motor trail, aktivitas memotong rumput dan aktivitas memancing. Aktivitas seperti ini, sangat berpengaruh pada tanaman tingkatan pancang dan tumbuhan bawah yang dapat rusak.

\subsection{Strategi Pengelolaan Kawasan Taman Wisata Alam Danau Buyan-Danau Tamblingan}

Berdasarkan data hasil wawancara, pengamatan dan kuisioner terhadap perilaku, persepsi dan pengetahuan masyarakat desa penyangga dapat diidentifikasi beberapa faktor internal dan eksternal dalam pengelolaan TWA Danau Buyan-Danau Tamblingan, sebagai berikut:
A. Faktor internal

1. Faktor kekuatan (strength),

a) TWA Danau Buyan Danau Tamblingan sebagai kawasan konservasi yang dilindungi negara

b) Potensi keanekaragaman hayati yang tinggi sebagai salah satu sanctuary.

c) TWA Danau Buyan Danau Tamblingan sebagai bagian Daerah Aliran Sungai (DAS) yang penting bagi Provinsi Bali mencakup sepertiga sumber air yang terdapat di Provinsi Bali.

d) Potensi wisata alam; wisata rimba, wisata tirta, wisata pendidikan dan penelitian serta wisata budaya.

2. Faktor kelemahan (weakness)

a) Kekurangan jumlah personil dalam pengawasan dan perlindungan terhadap kawasan TWA Danau Buyan-Danau Tamblingan

b) Aktivitas masyarakat yang merusak lingkungan

c) Lemahnya pembatasan akses masyarakat ke dalam kawasan hutan

d) Belum terbentuknya kearifan lokal dalam pengelolaan kawasan TWA Danau Buyan-Danau Tamblingan

B. Faktor eksternal

1. Faktor peluang (opportunity)

a) Kepedulian masyarakat adat dalam pelestarian kawasan yang disucikan

b) Keinginan masyarakat adat untuk terlibat dalam pengelolaan dan pemanfaatan kawasan hutan

c) Terdapat kelembagaan/organisasi yang terlibat dalam pelestarian dan perlindungan kawasan hutan

d) Peluang mata pencaharian baru bagi masyarakat dari pemanfaatan jasa lingkungan

2. Faktor ancaman (threat)

a) Aktivitas masyarakat menggunakan kendaraan bermotor dalam kawasan hutan

b) Aktivitas pengambilan kayu bakar oleh masyarakat yang dapat merusak vegetasi 
c) Adanya praktek illegall logging dan alih fungsi lahan yang pernah dilakukan masyarakat

d) Terjadi gangguan berupa erosi dan banjir di dalam kawasan hutan

Analisis IFAS dan EFAS dilakukan terhadap faktor internal dan ekternal, untuk mendapatkan kesimpulan analisis dari faktor internal maupun eksternal. Kesimpulan tersebut menghasilkan rumusan strategi yang dapat menyelesaikan permasalahan yang dihadapi. Hasil analisis IFAS dan EFAS dapat dilihat pada Tabel 2 dan Tabel 3.

Tabel 2. Analisis faktor internal

\begin{tabular}{|c|c|c|c|c|}
\hline No & Faktor Internal & Bobot & Rating & Skor \\
\hline $\mathbf{I}$ & Kekuatan & & & \\
\hline 1 & $\begin{array}{l}\text { TWA Danau Buyan Danau Tamblingan sebagai kawasan } \\
\text { konservasi yang dilindungi negara }\end{array}$ & 0,1 & 3 & 0,3 \\
\hline 2 & $\begin{array}{l}\text { Potensi keanekaragaman hayati yang tinggi sebagai salah } \\
\text { satu sanctuary }\end{array}$ & 0,1 & 2 & 0,2 \\
\hline 3 & $\begin{array}{l}\text { TWA Danau Buyan Danau Tamblingan sebagai bagian } \\
\text { Daerah Aliran Sungai (DAS) yang penting mencakup } \\
\text { sepertiga sumber air yang terdapat di Provinsi Bali }\end{array}$ & 0,1 & 3 & 0,3 \\
\hline 4 & $\begin{array}{l}\text { Potensi wisata alam; wisata rimba, wisata tirta, wisata } \\
\text { pendidikan dan penelitian serta wisata budaya }\end{array}$ & 0,1 & 2 & 0,2 \\
\hline I & Jumlah skor kekuatan & 0,4 & & 1,0 \\
\hline 1 & $\begin{array}{l}\text { Kekurangan jumlah personil dalam pengawasan dan } \\
\text { perlindungan terhadap kawasan TWA Danau Buyan- } \\
\text { Danau Tamblingan }\end{array}$ & 0,1 & -3 & $-0,3$ \\
\hline 2 & $\begin{array}{l}\text { Aktivitas masyarakat yang merusak lingkungan } \\
\text { Lemahnya pembatasan akses masyarakat ke dalam }\end{array}$ & 0,1 & -3 & $-0,3$ \\
\hline 3 & kawasan hutan & 0,1 & -3 & $-0,3$ \\
\hline 4 & $\begin{array}{l}\text { Belum terbentuknya kearifan lokal dalam pengelolaan } \\
\text { kawasan TWA Danau Buyan-Danau Tamblingan }\end{array}$ & 0,1 & -3 & $-0,3$ \\
\hline & $\begin{array}{l}\text { Jumlah skor kelemahan } \\
\text { Total (Kekuatan+kelemahan) }\end{array}$ & 0,4 & & $\begin{array}{l}-1,2 \\
-\mathbf{0}, 2\end{array}$ \\
\hline
\end{tabular}

Keterangan:

1. Bobot diberikan untuk masing-masing elemen sesuai dengan tingkat penting relatif terhadap keberhasilan pencapaian tujuan.

2. Rating untuk faktor kekuatan: rating 3 untuk kategori sangat kuat; 2 untuk kategori kuat, dan 1 untuk kategori cukup kuat. Rating untuk kelemahan: rating -3 untuk kategori sangat lemah; -2 untuk kategori lemah, dan -1 untuk kategori cukup lemah.

Tabel 3. Analisis faktor eksternal

\begin{tabular}{lllcc}
\hline No & Faktor Internal & Bobot & Rating & Skor \\
\hline $\mathbf{I}$ & $\begin{array}{l}\text { Peluang } \\
\text { Kepedulian masyarakat adat dalam pelestarian } \\
\text { kawasan yang disucikan }\end{array}$ & 3 & 0,1 \\
2 & $\begin{array}{l}\text { Keinginan masyarakat adat untuk terlibat dalam } \\
\text { pengelolaan dan pemanfaatan kawasan hutan }\end{array}$ & 0,1 & 3 & 0,3 \\
3 & $\begin{array}{l}\text { Terdapat kelembagaan/organisasi yang terlibat dalam } \\
\text { pelestarian dan perlindungan kawasan hutan }\end{array}$ & 3,1 & 0,3 \\
4 & $\begin{array}{l}\text { Peluang mata pencaharian baru bagi masyarakat dari } \\
\text { pemanfaatan jasa lingkungan } \\
\text { Jumlah skor peluang }\end{array}$ & $\mathbf{0 , 4}$ & 0,3
\end{tabular}




\begin{tabular}{lllcc}
\hline No & Faktor Internal & Bobot & Rating & Skor \\
\hline II & $\begin{array}{l}\text { Ancaman } \\
\text { Aktivitas masyarakat menggunakan kendaraan } \\
\text { bermotor dalam kawasan hutan }\end{array}$ & 0,1 & -3 & $-0,3$ \\
2 & $\begin{array}{l}\text { Aktivitas pengambilan kayu bakar oleh masyarakat } \\
\text { yang dapat merusak vegetasi }\end{array}$ & 0,1 & -2 & $-0,2$ \\
3 & $\begin{array}{l}\text { Adanya praktek illegall logging dan alih fungsi lahan } \\
\text { yang pernah dilakukan masyarakat }\end{array}$ & -3 & $-0,3$ \\
4 & $\begin{array}{l}\text { Terjadi gangguan berupa erosi dan banjir di dalam } \\
\text { kawasan hutan } \\
\text { Jumlah skor ancaman } \\
\text { Total (Peluang+Ancaman) }\end{array}$ & -3 & $-0,3$ \\
\hline
\end{tabular}

Keterangan:

1. Bobot diberikan untuk masing-masing elemen sesuai dengan tingkat penting relatif terhadap keberhasilan pencapaian tujuan.

2. Rating untuk faktor peluang: rating 3 untuk kategori sangat berpeluang; 2 untuk kategori berpeluang dan 1 untuk kategori cukup berpeluang. Rating untuk ancaman: rating -3 untuk kategori sangat mengancam; -2 untuk kategori mengancam, dan -1 untuk kategori cukup mengancam.

Berdasarkan matriks analisis SWOT terdapat 10 strategi alternatif dalam pengelolaan kawasan hutan di TWA Danau Buyan- Danau Tamblingan dalam kaitanya dengan peningkatan potensi cadangan karbon yang tersimpan di dalamnya, yaitu sebagai berikut:

Strategi SO, strategi yang menggunakan kekuatan untuk memanfaatkan peluang:

1. Memberikan sosialisasi proses pengajuan Izin Pengusahaan Pariwisata Alam (IPPA)

2. Memberikan bimbingan teknis/pelatihan kepada lembaga/ organisasi terkait kawasan hutan dan DAS

Strategi ST, strategi yang menggunakan kekuatan untuk memanfaatkan ancaman:

1. Memberikan sosialisasi kepada masyarakat desa tentang hutan dan peraturan perundang-undangan

2. Menetapkan blok rehabilitasi dalam kawasan hutan TWA Danau BuyanDanau Tamblingan
Strategi WO, strategi yang meminimalkan kelemahan untuk memanfaatkan peluang:

1. Melakukan pendampingan kepada desa adat dalam mengajukan Izin Pengusahaan Pariwisata Alam (IPPA)

2. Memfasilitasi masyarakat desa adat untuk mendapatkan pengakuan atas hutan adat

3. Merumuskan bentuk awig-awig sebagai kearifan lokal dalam pengelolaan kawasan TWA Danau Buyan-Danau Tamblingan

Strategi WT, strategi yang meminimalkan kelemahan untuk menghindari ancaman:

1. Meningkatkan kuantitas patroli pengamanan hutan

2. Mengusulkan penambahan jumlah personil polhut

3. Menindak tegas pelaku tindak pidana kehutanan sebagai efek jera. 


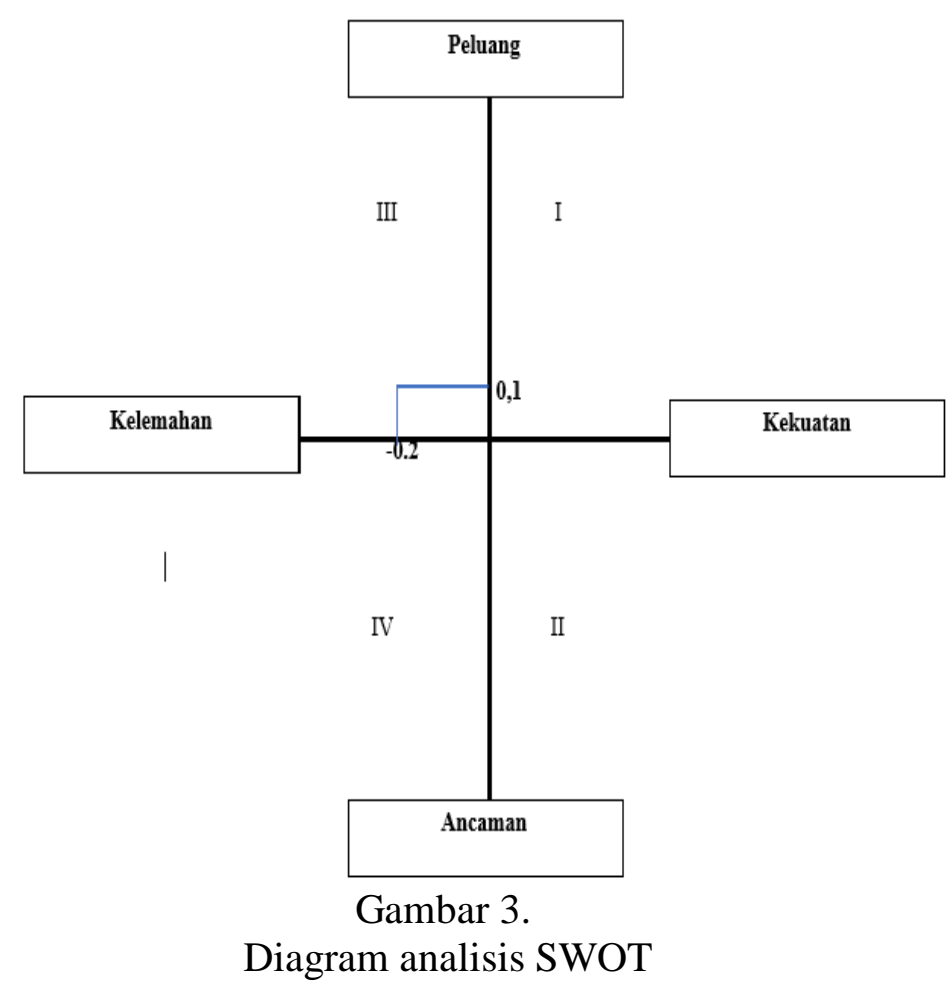

Pertemuan titik singgung IFAS dan EFAS berada pada kuadran III. Hal ini berarti bahwa sekalipun pengelolaan TWA Danau Buyan-Danau Tamblingan memiliki kendala berupa kelemahan, namun terdapat peluang yang besar dari keinginan masyarakat adat untuk terlibat dalam pelestarian lingkungan sekitarnya. Strategi yang dapat diterapkan adalah strategi yang meminimalkan kelemahan untuk memanfaatkan peluang (WO).

\section{SIMPULAN DAN SARAN}

\subsection{Simpulan}

Berdasarkan hasil dan pembahasan, maka dapat dirumuskan beberapa simpulan sebagai berikut:

1. Cadangan karbon yang terdapat pada tiga karbon pool: atas permukaan tanah (pohon dan tumbuhan bawah), nekromassa (seresah), dan tanah di hutan Danau Buyan lebih kecil dibandingkan di hutan Danau Tamblingan dengan rincian sebagai berikut, hutan Danau Buyan, masing-masing: 613.03 ton/ha, 62.56 ton/ha dan 125.443 ton/ha sedangkan hutan Danau Tamblingan, masingmasing: 768.93 ton/ha, 105.26 ton/ha dan 360.711 ton/ha.

2. Faktor penyebab perbedaan cadangan karbon di hutan Danau Buyan dan Danau Tamblingan adalah sebagai berikut: keragaman jenis tanaman di hutan Danau Buyan lebih rendah dari hutan Danau Tamblingan dan aktivitas manusia terhadap hutan Danau Buyan lebih tinggi dibandingkan hutan Danau Tamblingan.

3. Strategi pengelolaan kawasan TWA Danau Buyan-Danau Tamblingan untuk mendukung peningkatan cadangan karbon hutan, adalah strategi WO, yaitu:

a. Melakukan pendampingan kepada desa adat dalam mengajukan Izin Pengusahaan Pariwisata Alam (IPPA).

b. Memfasilitasi masyarakat desa adat untuk mendapatkan pengakuan atas hutan adat.

c. Merumuskan bentuk awig-awig sebagai kearifan lokal dalam pengelolaan kawasan TWA Danau Buyan-Danau Tamblingan. 


\subsection{Saran}

Saran yang dapat diberikan dalam pengelolaan kawasan hutan terkait simpanan karbon adalah:

1. Pihak pengelola agar lebih meningkatkan pengawasan terhadap aktivitas masyarakat dalam kawasan hutan Danau Buyan baik kegiatan wisata, maupun mencari pakan ternak, dan memancing. Agar Ketika masyarakat melakukan aktivitas-aktivitas tersebut tidak menggunakan kendaraan bermotor dalam kawasan sehingga tidak merusak tumbuhan bawah.

2. Perlunya mengidentifikasi jenis tanaman lokal yang memiliki kemampuan menyimpan karbon tinggi, untuk dijadikan pemilihan jenis tanaman reboisasi.

3. Perlu adanya penelitian lebih lanjut yang mengkombinasikan metode remotesensing \& pengukuran lapangan, sebagai salah satu persyaratan didalam mengikuti mekanisme perdagangan karbon.

\section{DAFTAR PUSTAKA}

BLH. 2012. Kajian Restorasi Danau Tamblingan dan Danau Buyan. BLH Provinsi Bali.

BSN. 2011. Pengukuran dan Perhitungan Cadangan Karbon Pengukuran Lapangan untuk Penaksiran Cadangan
Karbon Hutan (Ground based Forest Carbon Accounting). Jakarta: Badan Standarisasi Nasional.

Hairiah, K., et al. 2011. Pengukuran Cadangan Karbon dari Tingkat Lahan ke Bentang Lahan Edisi ke 2. World Agroforestry Centre, Bogor

Hairiah, K., R. Subekti, 2007. Pengukuran Karbon Tersimpan di Berbagai Macam Penggunaan Lahan. World Agroforestry Centre, Bogor.

Holdgate, M. 1995. Greenhouse Gas Balance in Forestry Opening Address to FRCC Conference. Forestry, 68(4): 297-302

Ketterings QM, Coe R, van Noordwijk M, Ambagau Y, Palm CA. 2001. Reducing uncertainty in the use of allometric biomass equations for predicting above-ground tree biomass in mixed secondary forests. Forest Ecology and Management. 120: 199-209.

Sutomo, dan I. D. P. Darma. 2011. Analisis Vegetasi di Kawasan Hutan Danau Buyan Tamblingan Bali Sebagai Dasar untuk Manajemen Kelestarian Kawasan. Jurnal Bumi Lestari 11(1): 78-84.

Ulum, S. 2009. Manfaat Beringin Putih dalam Pembangunan Kawasan Hutan. Kabar Indonesia. Jakarta. 